\title{
Polymer Photonic Sensing Skin
}

\author{
X. Chen ${ }^{\mathrm{a}}$, C. Zhang ${ }^{\mathrm{a}}$, D. J. Webb ${ }^{\text {a }}$, B. Van Hoe ${ }^{\mathrm{b}}$, G. Van Steenberge ${ }^{\mathrm{b}}, \mathrm{K} . \mathrm{Kalli}^{\mathrm{c}}$, F. Berghmans ${ }^{\mathrm{d}}$, \\ H. Thienpont ${ }^{\mathrm{d}}$, W. Urbanczyk ${ }^{\mathrm{e}}$, K. Sugden ${ }^{\mathrm{f}}$, G.- D. Peng ${ }^{\mathrm{g}}$ \\ ${ }^{a}$ School of Engineering and Applied Science, Aston University, Birmingham B4 7ET, UK; \\ ${ }^{\mathrm{b}}$ Ghent University-IMEC, Department of Electronics and Information Systems, Centre for \\ Microsystems Technology, B-9052 Zwijnaarde, Belgium; \\ ${ }^{\mathrm{c}}$ Nanophotonics Research Laboratory, Cyprus University of Technology, Cyprus; \\ ${ }^{\mathrm{d}}$ Brussels Photonics Team - B-PHOT, Vrije Universiteit Brussel, Belgium; \\ e Institute of Physics, Wroclaw University of Technology, Wybrzeze Wyspianskiego 27, 50-370 \\ Wroclaw, Poland; \\ ${ }^{\mathrm{f}}$ Astasense Ltd., 52 Torrin Drive, Shrewsbury, Shropshire, SY3 6AW, UK. \\ ${ }^{\mathrm{g}} \mathrm{School}$ of Electrical Engineering, University of New South Wales, Australia.
}

\begin{abstract}
A highly flexible sensing skin with embedded polymer optical fibre Bragg gratings is characterised The response to pressure and strain compare favourably to a similar skin instrumented with silica fibre Bragg grating sensors.
\end{abstract}

Keywords: Bragg grating, polymer optical fibre, sensor, pressure, strain.

\section{INTRODUCTION}

The Framework 7 project PHOSFOS (PHOtonic Skins For Optical Sensing) ${ }^{1}$ seeks to develop the technology to enable the production of flexible skins in which optical fibre Bragg grating (FBG) sensors, sources, detectors and signal processing electronics are integrated. Such a flexible skin could easily be deployed on irregular surfaces, which might be moveable (as in the case of tactile sensing applications for robotics) or could be folded into compact modules, for applications where size is an issue.

Two fibre types are being considered within this project, the first is based on novel designs of highly birefrigent photonic crystal fibre optimized to provide high pressure sensitivity whilst minimizing temperature cross-sensitivity. The second type of fibre, which is the subject of this paper, is polymeric and based on poly(methyl methacrylate) (PMMA). The technology of polymer optical fibre Bragg gratings is of much more recent origin than its silica equivalent; the first Bragg grating in step-index fibre was reported in $1999^{2}$ and the first in microstructured polymer optical fibre only in $2005^{3}$ (note though that grating structures in bulk PMMA were reported as early as $1970^{4}$ ).

There are a number of challenges with using polymer optical fibre (POF) Bragg gratings: firstly, polymers are viscoelastic and hence their mechanical behavior is more complex than that of silica. Secondly, the mechanical properties of polymer optical fibre are dependent on both the polymerization process used to create the fibre preform ${ }^{5}$ and the details of the drawing process. For example, we have measured the differential stress optical coefficient of fibre drawn at stress levels varying from 0.63 to $8.5 \mathrm{MPa}$. The result is negative at all drawing stresses and varies over a significant range from -4.5 to $-1.5 \times 10^{-12} \mathrm{~Pa}^{-1}$.

Despite these problems, the physical and chemical properties of POF are quite different to those of silica and offer some significant potential advantages in certain applications. Two of the most important differences relate to the mechanical properties of POF. Firstly, the elastic modulus of PMMA is approximately 25 times less than that of silica ${ }^{6}$, which means that much less force is required to produce a given strain in POF than in a silica fibre of the same diameter. Secondly, POF can supply much higher strains than silica fibre ${ }^{7}$.

Fourth European Workshop on Optical Fibre Sensors, edited by José Luís Santos, Brian Culshaw, José Miguel López-Higuera, William N. MacPherson, Proc. of SPIE Vol. 7653, 76533A

(C) 2010 SPIE · CCC code: $0277-786 \mathrm{X} / 10 / \$ 18 \cdot$ doi: $10.1117 / 12.866367$

Proc. of SPIE Vol. 7653 76533A-1 


\section{FIBRE EMBEDDING}

Within PHOSFOS new materials with controllable mechanical properties are being developed but for the purposes of the embedding trials reported here a thermally curable polydimethylsiloxane (PDMS) material, Sylgard®184 from Dow Corning, was chosen. In use, the liquid PDMS is mixed in the ratio 10:1 with hardener and can be left to cure at room temperature, though for the tests reported later the curing was carried out at $60^{\circ} \mathrm{C}$. The ability to cure at low temperatures is particularly important for POF gratings as they are destroyed at temperatures approaching the glass transition temperature of the PMMA, around $104^{\circ} \mathrm{C}^{6}$. The low temperature cure is also an advantage when embedding silica fibres because, although silica FBGs can survive much higher temperatures, cooling from these temperatures can lead to high stresses in the cured material due to the very large thermal expansion coefficient of the PDMS compared to the fibre ${ }^{6}$.

Three approaches have been developed for embedding the POF sensors in this material. The first and most straightforward is simply to use injection molding within a PMMA mold where the fibres are supported in channels at the edge of the mold. This approach was used for the optical tests reported later on but it has several disadvantages. Firstly, the only well definable fibre geometry that can be used is one where the fibres run straight from one side of the mold to another. Secondly, and particularly in the case of the rather elastic POF, even with tension in the fibre, it is difficult to ensure the fibre does not sag appreciably between the edge supports; this is particularly significant with thin skins as reported here. The second approach investigated was to use laser ablation to create tracks in a cured sheet of PDMS. Three laser systems have been tested for this purpose: KrF (248nm), frequency tripled Nd:YAG (355nm) and $\mathrm{CO}_{2}(10.6 \mu \mathrm{m})$. Of these three the $\mathrm{CO}_{2}$ laser proved best with the Sylgard material. Using the laser approach, arbitrary track shapes can be designed and the fibre then fixed in place with glue. The final approach studied starts with a silicon wafer substrate on which a layer of SU8 is spun and patterned by UV contact lithography to define the fibre positions. The resulting structure is then used as a mold for the PDMS material. Once this has been cured and removed, the fibre can be lain in the grooves defined by the SU8 tracks and either pressed into place or held using UV curable glue; the latter having the disadvantage of introducing a stiff interface between skin and fibre. Heat embossing is then used to lay a half cured top layer of PDMS over the whole skin with some uncured (liquid) PDMS acting as glue between the two halves of the skin.

\section{GRATING INSCRIPTION AND FABRICATION OF SKINS}

The POF used was a single mode step index PMMA based fibre (core diameter $9.5 \mu \mathrm{m}$, cladding diameter $200 \mu \mathrm{m}$ ). The FBG was inscribed by the scanning phase mask technique using a CW helium-cadmium laser (Kimmon model IK5652RG) with an output wavelength of $325 \mathrm{~nm}$, a beam diameter of $1.8 \mathrm{~mm}$ and a power of $30 \mathrm{~mW}$. A phase mask with period $1057 \mathrm{~nm}$ was used and the exposure time was approximately 30 minutes. Following inscription the $7.5 \mathrm{~cm}$ length of POF containing the grating was glued to a silica fibre pigtail. For comparison purposes silica FBGs were made in hydrogenloaded Corning SMF-28 fibre using a frequency doubled argon ion laser at $244 \mathrm{~nm}$ wavelength with a $1071.9 \mathrm{~nm}$ period phase mask. The silica FBGs were annealed at $85^{\circ} \mathrm{C}$ for 24 hours.

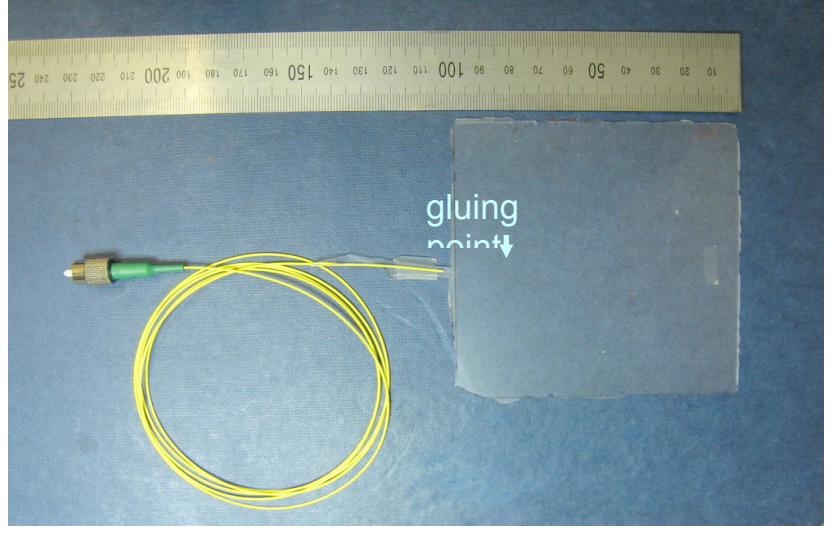

(a)

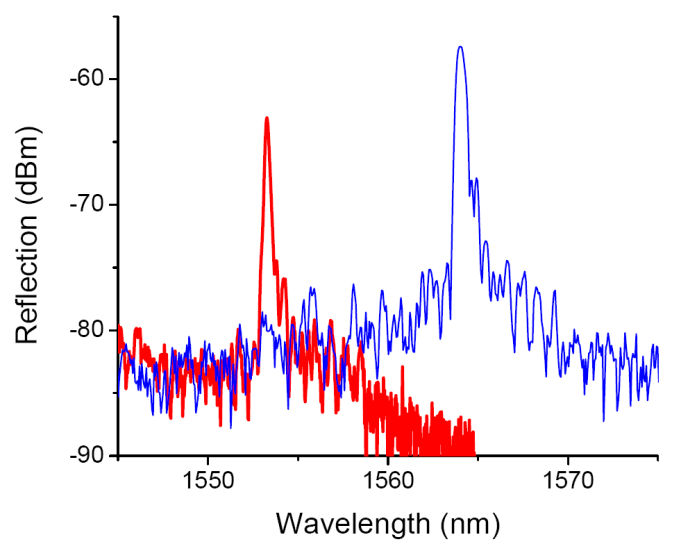

(b)

Figure 1. (a) PDMS skin containing POF grating and (b) the effect on the grating of the embedding process. 
The two gratings were embedded in PDMS by injection molding as described earlier; the result for the POF sensor is shown in Figure 2a. After the embedding the silica grating Bragg wavelength dropped by $0.84 \mathrm{~nm}$ while in the case of the POF the wavelength dropped by $10.75 \mathrm{~nm}$ (Figure 1b). The much larger shift in the POF FBG is likely to be partly a result of the POF's lower elastic modulus, which leads to it being affected more by the shrinkage of the PDMS on curing, and partly due to annealing of the grating ${ }^{8}$.

\section{SKIN CHARACTERISATION}

\subsection{Pressure}
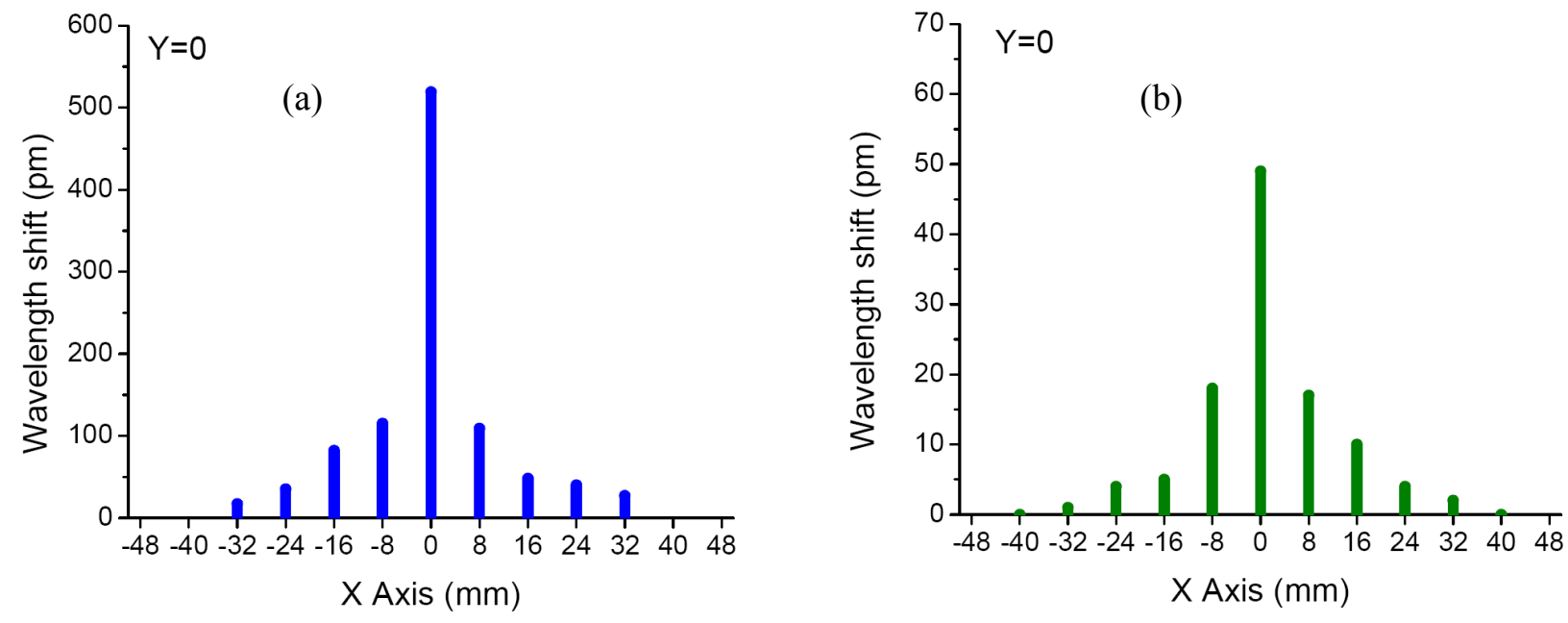

Figure 2. Wavelength shift as a function of position of load along fibre axis: (a) POF grating (b) silica FBG.

The samples of the photonic skins were placed on a rigid flat surface and the pressure was applied using a cylindrical metal post of mass $74 \mathrm{~g}$ and diameter $12 \mathrm{~mm}$. The response of the grating was recorded as the weight was moved over the grating along the line of the fibre axis, the results being shown in Figure 2. It may be seen from Figure 2 that for the same load the POF grating responds with a sensitivity approximately 10 times greater. This is attributable to its lower elastic modulus, the silica fibre offering much greater resistance to the stress that exists within the skin.

\subsection{Strain}
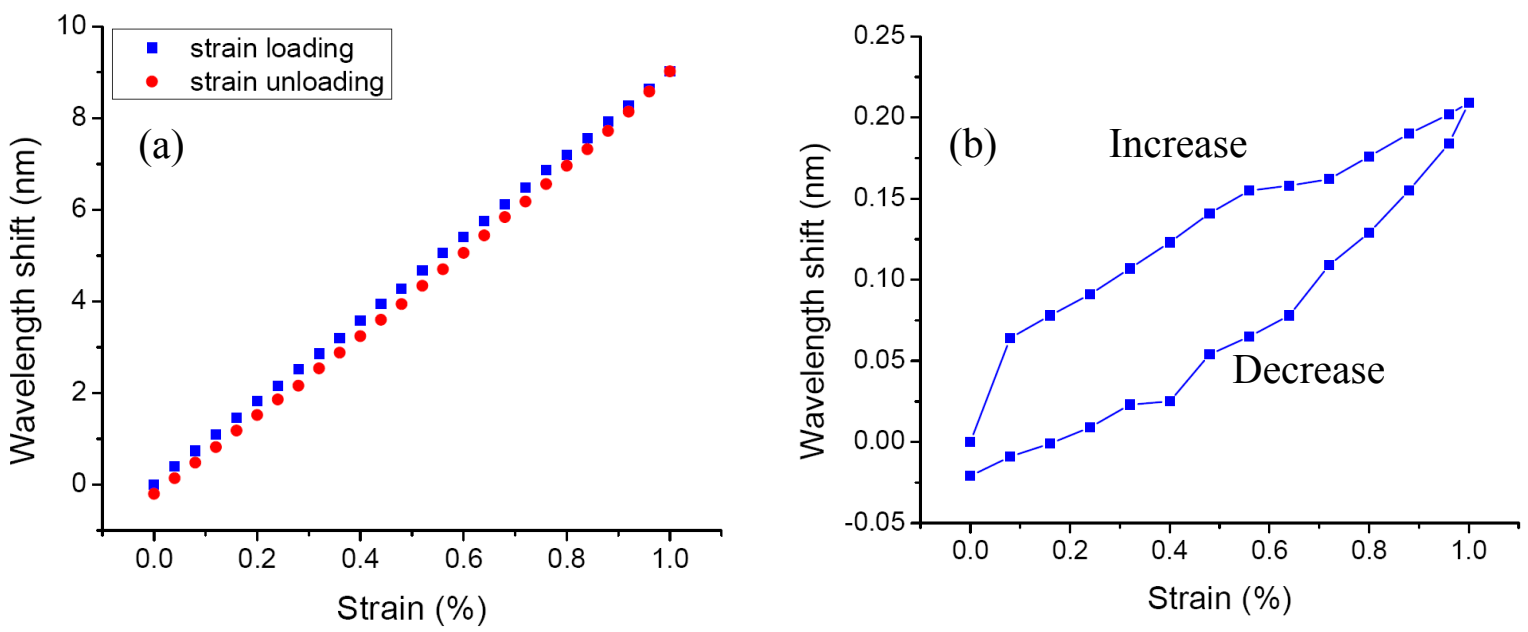

Figure 3. Wavelength shift of embedded FBGs as a function of applied strain: (a) POF grating (b) silica FBG. 
To characterise the sensitivity of the skins to strain, the skins were fixed to translation stages by melting 8 bolt holes in the material to enable it to be clamped with aluminium plates. The response to strain cycling is shown in Figure 3.The data for the POF FBG shown in Figure 3a exhibit good linearity, with just a small amount of hysteresis apparent when the fibre is unloaded. The total wavelength shift at $1 \%$ strain was $9 \mathrm{~nm}$, leading to a strain sensitivity of $0.9 \mathrm{pm} / \mu \varepsilon$, which is a little smaller than that reported for bare POF: $1.5 \mathrm{pm} / \mu \varepsilon^{2}$. The difference here is likely to arise from the mismatch in elastic moduli of the fibre and skin. The results for silica are shown in Figure $3 \mathrm{~b}$. It proved impossible to obtain data showing a smooth response and the data shown are typical. The response is nonlinear and displays considerable hysteresis. At $1 \%$ applied strain, the total wavelength shift is $0.21 \mathrm{~nm}$, which corresponds to a strain sensitivity of just $0.021 \mathrm{pm} / \mu \varepsilon$, whereas the bare-fibre sensitivity is $1.2 \mathrm{pm} / \mu \varepsilon^{9}$. The much stiffer silica fibre resists the stress in the skin much more than the POF and consequently is less able to report the true background strain in the skin.

\section{CONCLUSION}

We have described progress towards realizing a highly flexible sensing skin containing polymer optical fibre Bragg grating sensors. The use of polymeric fibre enables the sensors to respond much better to induced strain within the skin which leads to a pressure sensitivity an order of magnitude greater than for silica FBGs. When the skin is strained the POF is also able to respond better displaying good linearity with little hysteresis and a strain sensitivity close to that of the bare fibre. The silica fibre on the other hand is unable to respond well and exhibits both a great degree of hysteresis and reports very little of the background strain within this highly elastic skin.

\section{ACKNOWLEDGEMENTS}

The authors acknowledge the support of the European Commission through Project PHOSFOS (PHOtonic Skins For Optical Sensing).

\section{REFERENCES}

[1] http://www.phosfos.eu/.

[2] Z. Xiong, G. Peng, B. Wu et al., "Highly tunable Bragg gratings in single-mode polymer optical fibers," IEEE Photonics Technology Letters, 11(3), 352-354 (1999).

[3] H. Dobb, D. J. Webb, K. Kalli et al., "Continuous wave ultraviolet light-induced fiber Bragg gratings in fewand single-mode microstructured polymer optical fibers," Optics Letters, 30(24), 3296-3298 (2005).

[4] W. J. Tomlinson, I. P. Kaminow, A. Chandross et al., "Photoinduced refractive index increase in poly(methyl methacrylate) and its applications," Applied Physics Letters, 16, 486-489 (1970).

[5] L. Dvoianek, L. Machova, M. Sorm et al., "Effects of Drawing Conditions on the Properties of Optical Fibers Made from Polystyrene and Poly(Methy1 Methacrylate)," Die Angewandte Makromolekulare Chemie, 174, 2539 (1990).

[6] J. Brandrup, [Polymer Handbook] Wiley, V89 (1999).

[7] S. Kiesel, K. Peters, T. Hassan et al., "Behaviour of intrinsic polymer optical fibre sensor for large-strain applications," Measurement Science \& Technology, 18(10), 3144-3154 (2007).

[8] K. E. Carroll, C. Zhang, D. J. Webb et al., "Thermal response of Bragg gratings in PMMA microstructured optical fibers," Optics Express, 15(14), 8844-8850 (2007).

[9] A. D. Kersey, M. A. Davis, H. J. Patrick et al., "Fiber grating sensors," Journal of Lightwave Technology, 15(8), 1442-1463 (1997). 